\title{
O Diretório dos Grupos de Pesquisa do CNPq e a Interação Universidade-Empresa no Brasil em 2004*
}

\section{Márcia Siqueira Rapini}

Mestre em Economia pelo IE/UFRJ; Consultora Interna do Instituto Euvaldo Lodi - IEL/ FIEMG

\section{Hérica Morais Righi}

Economista pela UFMG; Pesquisadora Associada do Núcleo SERASA de Inovação da Fundação Dom Cabral

RESUMO

O presente trabalho apresenta informações do Diretório dos Grupos de Pesquisa do CNPq que podem ser exploradas na investigação da interação universidade-empresa no Brasil. Para tal são utilizados como proxy os grupos de pesquisa cadastrados no CNPq que declararam algum relacionamento com o setor produtivo. As informaçôes foram extraídas do Censo 2004 do Diretório dos Grupos de Pesquisa do CNPq. Os resultados mostram a maior freqüência das atividades de pesquisas científicas e de transferência de tecnologia que se caracterizam como trocas bidirecionais de conhecimento. Esse panorama pode estar apontando para avanços no desenvolvimento de uma linguagem comum entre os grupos de pesquisa e o setor produtivo. Esta investigação ilustra especificidades recentes do Sistema Nacional de Inovação do País, indicando que ainda há espaço para incentivos que fomentem a transferência do conhecimento acadêmico para as empresas.

\footnotetext{
* Este texto é uma versão modificada do Texto para Discussão do CEDEPLAR Nº 287 (2006).

Agradecemos aos pareceristas anônimos a leitura atenciosa e pontual, e as sugestões enviadas, que nos ajudaram não apenas a melhorar este artigo, como também a percepção sobre o assunto.
} 
Palavras-Chave | Interação Universidade-Empresa; Grupos de Pesquisa; Diretório dos Grupos de Pesquisa do CNPq

Códigos JEL | O30, O39

\section{ABSTRACT}

This paper uses a specific database on research groups from CNPq (National Council for Scientific and Technological Development) to investigate university-industry interactions in Brazil. Only research groups that declare any relationship with the productive sector are used as proxies for those interactions. The data were collected from CNPq 2004 Census on Research Groups Directory. Although with limitations intrinsic to the kind of information collected, the database supplies useful evidence from recent university-industry interactions in the country. The most frequent relationships are scientific research and technology transference that are characterized as bi-directional knowledge flows, what suggests advances in the development of a common language between universities and firms. Such results illustrate a specificity of the Brazilian National System of Innovation, but they also suggest that there is ample room for new incentives to foster academic knowledge transference to firms in the country.

KEYWORDS | University-Industry Interactions, Research Groups; CNPq Research Groups Directory

JEL CODES $\mid$ O30, O39 


\section{Introdução}

Uma importante característica da interação universidade-empresa é que ela é específica a cada país e depende da infra-estrutura nacional de Ciência e Tecnologia (C\&T). Atrás dessa idéia, está o arcabouço teórico desenvolvido a partir da literatura de Sistema Nacional de Inovação (SNI) que teve início em 1992 por Bengt-Ake Lundvall. A literatura enfatiza a importância da existência de fortes interações entre as diversas instituições e as empresas no desenvolvimento de novos conhecimentos científicos e tecnológicos, ferramentas propulsoras do processo inovativo e do desenvolvimento competitivo dos países (Mowery et al., 2005).

As contribuições das universidades para o processo inovativo nas empresas são sintetizadas como: fonte de conhecimento de caráter mais geral necessários para as atividades de pesquisa básica (Nelson, 1990); fonte de conhecimento especializado relacionado à área tecnológica da firma (Klevorick et al., 1995); formação e treinamento de engenheiros e cientistas capazes de lidar com problemas associados ao processo inovativo nas firmas (Rosenberg \& Nelson, 1994; Pavitt, 1998); criação de novos instrumentos e de técnicas científicas (Rosenberg, 1992); criação de firmas nascentes (spin-offs) por pessoal acadêmico (Stankiewics, 1994).

Para o Brasil, que vem buscando uma maior competitividade em termos globais e maior inserção no paradigma da microeletrônica, a capacidade de criação de conhecimento interno torna-se pré-requisito fundamental. Apesar de ainda deficitário em termos de formação de mão-de-obra qualificada, o País conta com expressiva comunidade acadêmica e científica. Contudo, o aproveitamento da infra-estrutura de conhecimento pelo setor privado é muito aquém do desejado. Uma das formas de potencializar esse processo é pelo do aumento da interação das universidades com as empresas, uma vez que as universidades propiciem redirecionar as atividades produtivas das empresas para avanços inovativos em produtos e processos.

A literatura que investiga a interação universidade-empresa é empírica, baseada em três fontes de informação: estudos de caso, análises de patentes e bibliométricas ou em grandes pesquisas/levantamentos. Este trabalho explora esse tema para o Brasil com base nas informaçôes disponíveis no Diretório dos Grupos de Pesquisa do CNPq, referentes ao Censo 2004. São apresentadas, em 
termos gerais, as informações disponíveis no Diretório e algumas das possíveis agregações e formas de análise dos dados. A metodologia proposta buscou ajustar o questionário aos objetivos do trabalho, consistindo em uma proposta preliminar. Essa base de dados, apesar de não contar com o nível de detalhamento de estudos empíricos, abrange um número maior de instituiçôes em várias localidades do País, sendo, ademais, informações recentes.

Além dessa introdução, o trabalho conta com mais cinco seções, sendo a segunda uma revisão da literatura referente à interação universidade-empresa. A terceira seção é uma revisão da interação universidade-empresa no Brasil, trazendo também os resultados da Pesquisa Industrial de Inovação Tecnológica do IBGE (PINTEC). A quarta é uma breve descrição do Diretório dos Grupos de Pesquisa do CNPq e das informações disponíveis, e a quinta seção descreve a metodologia adotada na realização do trabalho. A sexta introduz a interação universidade-empresa a partir das informações disponíveis no Diretório dos Grupos de Pesquisa do CNPq, por meio de duas perspectivas diferentes: pela área do conhecimento dos grupos de pesquisa e pelo tamanho dos estabelecimentos do setor produtivo. Por fim, a conclusão do presente trabalho.

\section{Interação universidade-empresa: revisão da literatura}

A interação universidade-empresa é um importante subconjunto institucional do amplo sistema de troca de conhecimento. As empresas devem desenvolver competências tecnológicas que possibilitem a absorção efetiva de conhecimento gerado nas universidades. Da mesma forma, a contribuição das universidades e o aumento da interação só são possíveis na medida que o crescimento do conhecimento possa assumir forma e conteúdo de assistência direta para as necessidades de mudança dos vários setores industriais (Rosenberg \& Nelson, 1994).

O entendimento da interação universidade-empresa não pode se dar de forma dissociada do desenvolvimento e consolidação dos Sistemas Nacionais de Inovação. A intensidade das interaçooes universidade-empresa depende da "capacidade estrutural de absorção", ' referentes às empresas, universidades e instituições de pesquisa, e do sistema de inovação, como identificado por Meyer-

\footnotetext{
Dependem de características ao nível meso (intensidade da ciência nas tecnologias, ciclo de vida da indústria e tamanho das firmas do setor industrial) e micro (capacidade de P\&D interno das firmas, padrões de interação de tecnologias relevantes além dos tradicionais e redes informais e formais de cooperação).
} 
Kramer e Schmoch (1998). Estes autores apontam para o caráter fortemente path dependency da interação universidade-empresa que enfrenta problemas estruturais de ausência de reconhecimento e da adoção de novos paradigmas tecnológicos e trajetórias tecnológicas de forma rápida o suficiente.

Um dos aspectos importantes nesta investigação é, portanto, o impacto que a base industrial nacional desempenha na estrutura das universidades via demanda por estudantes bem treinados e qualificados. Os investimentos em pesquisa básica surtirão efeitos distintos dependendo de como se dão os elos entre as empresas e as instituições geradoras de conhecimento (Lundvall, 2002). Neste sentido, a presença de empresas multinacionais e de capital estrangeiro em setores industriais relevantes ou orientados internacionalmente compromete o processo de troca de conhecimento por meio da interação universidadeempresa, que tende a acontecer com o exterior (Schartinger et al., 2002).

A partir dos anos 1980, as interações entre universidades e empresas intensificaram-se com o aumento do fluxo de conhecimento. Diversos novos mecanismos institucionais de transmissão de tecnologia entre universidades e empresas foram desenvolvidos como parques tecnológicos ao redor de universidades, escritórios de transferência nas universidades e institutos de pesquisas híbridos coordenados por universidades e empresas (Schimank, 1988). Paralelamente os fenômenos do Vale do Silício e da Rodovia 129 nos EUA e de Cambridge, na Inglaterra, reforçaram a contribuição das universidades no desenvolvimento local pela criação de firmas de alta tecnologia em regiōes próximas (Varga, 1997).

Dentre as razões atribuídas à aproximação das universidades com o setor produtivo identifica-se: aumento dos custos de realização de atividades de P\&D na indústria e na academia, redução dos recursos públicos governamentais para as atividades de pesquisa acadêmica e emergência de novo paradigma no qual reduziu-se a distância entre a inovação e aplicação tecnológica (Brisolla et al., 1997).

A relevância das pesquisas acadêmicas no processo inovativo dá-se por diversas formas e mecanismos, sendo limitada e muitas vezes de forma indireta. Por parte das firmas é fortemente associada às oportunidades tecnológicas e ao grau de apropriabilidade enfrentados pelo setor de atividade, e por parte das universidades é variante de acordo com as áreas do conhecimento (Klevorick et al., 1995).

Por parte do setor público de pesquisa, elementos como qualidade do corpo docente, qualidade das pesquisas realizadas, tamanho dos departamentos universitários, estrutura de pessoal (pesquisadores seniores) e publicações inter- 
nacionais aparecem como decisivos no engajamento de cooperação com o setor produtivo (Mansfield \& Lee, 1996; Schartinger et al., 2001). Por parte das empresas o mesmo é compelido pelo tamanho da empresa, estrutura do capital, saúde financeira, setor de atividade, existência de base de conhecimento e da propensão à interação.

Em termos de fontes de informações as mais freqüentes têm sido: contatos pessoais/informais, publicações, encontros e conferências, consultorias, recrutamento de pessoal, treinamento de pessoal, patentes e licenciamentos. Em geral, essas fontes são complementares na busca do conhecimento de fronteira, sendo estrategicamente combinadas pelas empresas (Faulkner \& Senker, 1994; Cohen et al., 2002; Meyer-Kramer \& Schmoch, 1998; Schartinger et al., 2001).

A formalização da cooperação, por outro lado, também é variante. Ao passo que a parceria em pesquisas estaria constituindo uma troca bidirecional de conhecimento (Meyer-Kramer \& Schmoch, 1998), os contratos de pesquisa seriam mecanismos irregulares de transferência de conhecimento, constituindo em estratégias de baixo custo de entrada exigindo relativamente pequenas capacidades de absorção e de transferência de um dos lados (Schartinger et al., 2002). Ademais, colaborações formais estão vinculadas às estratégias de firmas inovadoras (Monjon \& Waelbroeck, 2003).

Dentre os benefícios oriundos de interações com o setor de pesquisa público enumera-se: desenvolvimento de protótipos e de novas técnicas e instrumentos, sugestão de novas idéias, assistência na complementação de projetos existentes, fornecimento de materiais para o desenvolvimento de produtos durante o período inicial da firma na tecnologia, acesso ao conhecimento tecnológico (Faulkner \& Senker, 1994; Cohen et al., 2002).

Outro fator amplamente investigado é a importância da proximidade geográfica na interação universidade-empresa e a contribuição das universidades no desenvolvimento local. Os trabalhos realizados visaram identificar os efeitos de "transbordamento" (spill-overs) do componente tácito do conhecimento científico gerado nas universidades para as atividades de P\&D industrial (Jaffe et al., 1993; Acts et al., 1992), a importância de colaborações informais e contatos face a face em regiōes de alta tecnologia (Varga, 1997; Mansfield \& Lee, 1996), e a contribuição da infra-estrutura de pesquisa no desenvolvimento de capacidades inovativas em regiōes (Dorfman, 1989).

Resultados apontam que a importância da proximidade geográfica é va- 
riante de acordo com a intensidade de P\&D, tamanho da empresa, grau de formalização das relações e existência de institucionalidade local. A proximidade geográfica por si mesmo, apesar de condição necessária, não é suficiente para a existência de interações que levem à transmissão do conhecimento. Outros fatores como economias de codificação do conhecimento, mercado de trabalho e estratégias de apropriação também explicam o fenômeno da localização (Breschi \& Lissoni, 2001).

Um importante fenômeno na transferência de conhecimento acadêmico é a criação de firmas spin-off por pesquisadores ou estudantes nas vizinhanças de universidades. De acordo com Stankiewics (1994) as firmas spin-offs são a tentativa de criação de um espaço institucional para as atividades não condizentes com as estruturas já estabelecidas na academia e nas empresas, que permitem ao cientista e ao engenheiro preservarem suas identidades próprias ao mesmo tempo em que adquirem novos papéis no processo de comercialização de tecnologia. No caso específico da biotecnologia, é uma das formas existentes de apropriação do valor econômico do conhecimento não viabilizado de outras maneiras (Audretsch \& Stephan, 1996).

Portanto, a contribuição das atividades acadêmicas varia de acordo com área do conhecimento (Salter \& Martin, 2001) e setor de atividade (Klevorick et al., 1995; Cohen et al., 2002). Da mesma forma as características do sistema tecnológico irão influenciar a contribuição funcional das universidades (Faulkner \& Senker, 1994; Meyer-Kramer \& Schmoch, 1998) em termos dos mecanismos formais ou informais com aplicação direta ou indireta.

\section{Interação universidade-empresa no Brasil}

No Brasil, durante o processo de industrialização, o principal obstáculo à interação das empresas com universidades foi a ausência de demanda por tecnologia no processo produtivo. Os anos 1980 caracterizaram-se por algumas iniciativas nesta direção, tendo sido adotado de forma mais sistemática a partir de meados da próxima década, inclusive em termos de programas governamentais.

Nos anos 1990, a Política Industrial e de Comércio Exterior atribuiu significativa importância à associação entre universidades e empresas na modernização tecnológica do parque industrial nacional e no aumento da participação do setor privado nos investimentos de C\&T (Velho, 1996). No âmbito federal 
foram criados programas especiais tendo como objeto a pesquisa aplicada e o desenvolvimento experimental nas áreas de engenharias (Rappel, 1999). O maior deles foi uma ação conjunta dos ministérios da Ciência e Tecnologia e da Educação que criaram o programa de Redes Cooperativas de Pesquisa (RECOPE), para estimular e apoiar a constituição de redes de instituições de pesquisa e empresas em torno de projetos cooperativos. Na esfera do III Programa de Apoio ao Desenvolvimento Científico e Tecnológico (PADCT), o Projeto Plataforma foi criado para apoiar a integração dos esforços entre universidades, institutos de pesquisa e empresas industriais na geração de projetos cooperativos. ${ }^{2}$

Adicionalmente a esses programas, foram concebidos incentivos fiscais às empresas para o investimento em atividades de P\&D realizadas em parceria com universidades ou instituições de pesquisa, por meio das leis nº 8.248 de 1991 e 8.661 de 1993. Esse conjunto de incentivos, até setembro de 1995, beneficiou 27 programas de desenvolvimento tecnológico, referentes a 26 empresas isoladas e a um consórcio abrangendo 40 empresas (Silva \& Mazzali, 2001). Em 2000, foi instituído o projeto de lei no 10.168 que regulamentou a criação de um fundo setorial para incentivar a interação entre universidades e empresas no desenvolvimento científico e tecnológico brasileiro, o Fundo Verde-Amarelo. Mais recentemente foi sancionada a lei no 3.476 de 2004, a Lei de Inovação, com objetivo de favorecer o investimento de empresas em pesquisa científica e tecnológica no País. No mesmo ano foi aprovada a lei oㅡㄴ 10.973 oficializando o estímulo à interação entre as Instituições Científicas e Tecnológicas (ICTs) e empresas. ${ }^{3}$

No nível estadual observa-se também a criação de mecanismos específicos ao estímulo à cooperação da comunidade acadêmica com o setor empresarial provenientes das Fundaçóes de Amparo à Pesquisa (FAP). A FAPERG, em 1989, lançou o primeiro edital de projetos de pesquisa que assegurassem a integração universidade e empresa e até 1998 financiou cerca de 200 projetos (Vargas et al., 1999). A FAPESP vem criando "mecanismos para intensificar a disseminação do conhecimento, tornando-o mais acessível à empresa” (Cruz, 1999:235) com a

2 Dentre os dez programas apoiados pelo PADCT em 1998 destaca-se o Programa de Automação Industrial na Bahia envolvendo oito indústrias petroquímicas e duas universidades tendo gerado sete projetos cooperados.

3 Entre as premissas desta lei está o compartilhamento de infra-estrutura, participação dos pesquisadores nos lucros auferidos sob os produtos criados pelas instituições, cessão temporária dos pesquisadores das ICTs para as empresas e concessão de recursos financeiros, humanos e de infra-estrutura por parte do governo para as empresas destinados a apoiar atividades de P\&D. 
criação de programas como o de Parceria para Inovação Tecnológica (PITE) e o de Inovação na Pequena Empresa (PIPE). Mais recentemente, algumas FAPs, por meio da FINEP/MCT, implantaram o Programa de Apoio à Pesquisa em Empresas (PAPPE) com objetivo de promover o desenvolvimento tecnológico das empresas, induzindo-as à aproximação com instituições de ensino e pesquisa. Dentre os estados já beneficiados com o programa estão Minas Gerais, Rio Grande do Sul, Rio de Janeiro, Bahia e Mato Grosso do Sul.

Do lado das empresas, têm-se iniciativas recentes dos Institutos Euvaldo Lodi com a criação dos Fóruns de Tecnologia (ForumTec) no Ceará (em 1996), na Bahia (em 1997) e em Minas Gerais (em 2003) “cujo objetivo é articular as instituições que compõem o Sistema Estadual de C\&T, promovendo a geração de projetos cooperativos que captem recursos para o desenvolvimento tecnológico local” (Rappel, 1999:102). A Associação Nacional de Pesquisa e Desenvolvimento das Empresas Industriais (ANPEI), criada em 1984, mais recentemente também vem realizando iniciativas na aproximação entre a indústria e a universidade.

Entre problemas identificados em estudos de caso que refletem ineficiências e fragilidades das interações recentes entre universidades e empresas no País, reúne-se: baixo conteúdo científico e curto prazo requerido para as soluções industriais que não estimula os contratantes a investirem em C\&T; ausência de interlocutores adequados nas empresas dificultando a comunicação; setor produtivo pouco inovativo; ausência de instrumentos adequados nas universidades para a comercialização de tecnologia; pouca flexibilidade das instituições de C\&T (Rapini, 2004).

A Pesquisa Industrial de Inovação Tecnológica (PINTEC), realizada em 2000 e 2003 pelo Instituto Brasileiro de Geografia e Estatística (IBGE), é um dos panoramas recentes que ajudam a entender a situação da inovação tecnológica no Brasil. A pesquisa aponta para um baixo nível de inovação dentro das empresas brasileiras. No biênio 2001-2003 apenas 33,3\% do total das empresas implementaram algum tipo de inovação, reflexo de poucos investimentos em atividades de P\&D por parte do setor privado.

A principal fonte de incorporação e desenvolvimento de novas tecnologias industriais foi via aquisição de máquinas e equipamentos (80,3\% das empresas atribuíram alta e média importância). Em concordância, as principais fontes de 
informação para a implementação de inovações foram oriundas de interações de natureza comercial (com fornecedores, clientes, consumidores e empresas concorrentes), em detrimento de fontes de informações institucionais como as provenientes de universidades e instituições de pesquisa.

$\mathrm{Na}$ mesma direção, a cooperação com demais organizações na implementação de atividades inovativas e na realização de projetos de $\mathrm{P} \& \mathrm{D}$ foi pouco utilizada pelas empresas industriais no Brasil. Do conjunto das empresas inovadoras em 2003 somente 4\% valeram-se deste tipo de estratégia. Em termos de parceiros, a maior proporção de relações de cooperação foi com fornecedores $(55,6 \%)$ e clientes (42,4\%). A cooperação com universidades e institutos de pesquisa em 2003 apresentou crescimento relativo a 2000, alcançando 16\% do total das empresas. Das empresas que inovaram e receberam apoio do governo (19\%), apenas 7\% valeram-se de financiamento para projetos de pesquisa em parceria com universidades e institutos de pesquisa.

De acordo com a investigação de Albuquerque et al. (2005) ${ }^{4}$ sobre a PINTEC de 2000, as empresas que realizam algum tipo de P\&D (interno, externo ou ambos) atribuíram maior importância às universidades como fontes de informação para suas atividades inovativas $(21,1 \%$ do total das empresas) comparativamente às empresas que não realizam $\mathrm{P} \& \mathrm{D}(6,1 \%)$. Um aspecto relevante salientado pelos autores remete às empresas que não realizam atividades de $\mathrm{P} \& \mathrm{D}$, mas valorizam as universidades, em montante significativo (893 empresas) e próximo ao total das empresas que realizam atividades internas de $P \& D$ e valorizam as universidades. Uma das explicações sugeridas é que essas empresas estariam utilizando os recursos da universidade como substitutos do investimento interno, possivelmente em função da restrição de recursos financeiros.

\section{O Diretório dos Grupos de Pesquisa do CNPq}

O Diretório dos Grupos de Pesquisa do CNPq reúne informações sobre os grupos de pesquisa em atividade no País sendo: número de pesquisadores, estudantes, técnicos e linhas de pesquisa em andamento, os setores de atividades envolvidos, a produção científica, tecnológica e artística geradas pelos grupos e mais recentemente os padrões de interação dos grupos com o setor produtivo.

4 Foram solicitadas tabulações especiais ao IBGE. 
Cada grupo está situado no espaço (instituição, unidade da federação e região) e no tempo (CNPq, 2005).

Apesar de caracterizar-se por uma base de informações de preenchimento opcional, o universo abrangido pela mesma vem aumentando ao longo do tempo, podendo-se supor relativa representatividade da comunidade científica nacional. As universidades, instituições de ensino superior e institutos que ministram cursos de pós-graduação concentram mais de 90\% dos grupos de pesquisa cadastrados, não fazendo parte do diretório as empresas privadas (Carneiro \& Lourenço, 2003).

Os dados são capturados por meio do site do CNPq na Internet e as informações são coletadas por meio de um formulário eletrônico padronizado que os líderes dos grupos de pesquisa participantes têm acesso. As informações podem ser obtidas de duas formas: por meio da base corrente e da base censitária. Os censos são "fotografias" estáticas da base corrente realizadas de dois em dois anos (CNPq, 2005). A partir de 2002, a interação com o setor produtivo foi inserida no questionário a ser respondido pelos líderes dos grupos de pesquisa, passando a ser uma importante fonte de informação sobre a interação universidade-empresa no País. As informaçóes disponibilizadas nos censos podem ser extraídas no Plano Tabular que possibilita a formatação de tabelas de acordo com as variáveis disponíveis.

A primeira versão do Diretório dos Grupos de Pesquisa do CNPq de 1993 possuía 99 instituiçóes, 4.402 grupos de pesquisa cadastrados e 21.541 pesquisadores (Tabela 1). A última versão consolidada, de 2004, possui 375 instituiçôes, 19.470 grupos de pesquisa cadastrados e 77.649 pesquisadores. Cerca de 19\% das instituições em 2004 concentravam aproximadamente 75\% do total dos grupos de pesquisa. Desde a primeira versão do Diretório até 2004, expressivo aumento da parcela de doutores dentre os pesquisadores pode ser observado.

\section{Metodologia}

As informações a seguir apresentadas foram coletadas no Diretório dos Grupos de Pesquisa do CNPq, tendo sido obtidas mediante consultas na Internet. As consultas à base de dados foram realizadas no modulo "Plano Tabular" do Censo 2004. ${ }^{5}$ Este módulo disponibiliza um conjunto de variáveis que podem 
TABELA 1

Evolução do número de instituições, grupos de pesquisa, pesquisadores e doutores no Diretório dos Grupos de Pesquisa do CNPq, Brasil, 1993-2004

\begin{tabular}{|c|c|c|c|c|c|c|}
\hline & 1993 & 1995 & 1997 & 2000 & 2002 & 2004 \\
\hline Instituições & 99 & 158 & 181 & 224 & 268 & 375 \\
\hline Grupos & 4.402 & 7.271 & 8.632 & 11.760 & 15.158 & 19.470 \\
\hline Pesquisadores (P) & 21.541 & 26.799 & 34.040 & 48.781 & 56.891 & 77.649 \\
\hline Doutores (D) & 10.994 & 14.308 & 18.724 & 27.662 & 33.947 & 47.973 \\
\hline$(D) /(P)$ em \% & 51 & 53 & 55 & 57 & 60 & 62 \\
\hline
\end{tabular}

Fonte: Diretório dos Grupos de Pesquisa do CNPq.

ser agregadas na construção de tabelas, sendo o máximo de quatro tipos de variáveis por consulta. Foram realizadas inúmeras consultas de acordo com o propósito almejado. A escolha das variáveis a serem analisadas baseou-se na tentativa de trazer resultados comparáveis aos já realizados na literatura. Nem todos os cruzamentos possíveis foram explorados tendo em vista a necessidade de limitar o escopo do trabalho.

A informação referente aos tipos de relacionamentos entre os grupos de pesquisa com o setor produtivo é fornecida pelos líderes dos grupos. Existem 14 tipos de relacionamentos possíveis: ${ }^{6}$ nove oriundos dos grupos de pesquisa para o setor produtivo e cinco oriundos do setor produtivo para os grupos de pesquisa. Dentre os mesmos, há dois que não são necessariamente associados a relaçōes de interesse mútuo. ${ }^{7}$ Uma vez que o objetivo do trabalho é a identificação de interaçôes que reflitam projetos de colaboração entre os grupos de pesquisa e o setor produtivo optou-se por excluí-los da investigação.

Cada líder do grupo pode atribuir até três tipos de relacionamentos mais

\footnotetext{
5 As informações do Censo 2004 referem-se aos dados da base corrente de 21/10/2004 (CNPq, 2005).

6 Disponível em www.cnpq.br.

7 "Fornecimento de insumos materiais para as atividades do parceiro sem vinculação a um projeto específico de interesse mútuo."
} 
freqüentes com o setor produtivo. As informações disponibilizadas não permitem identificar o grau de relevância ou importância atribuído a cada tipo de relacionamento conforme estudos já realizados (Klevorick et al., 1995; Cohen et al., 2002), mas possibilitam fazer comparações entre os grupos. Tampouco há controle sobre limitações e problemas inerentes à coleta dos dados, decorrentes da subjetividade das percepções individuais.

Do total dos grupos de pesquisa cadastrados no Diretório em 2004, 2.151 (ou $11,1 \%$ do total) declararam algum tipo de relacionamento com o setor produtivo, sendo os mesmos vinculados a um total de 217 instituições. A próxima seção apresenta estes dados a partir das variáveis e dos níveis de agregação disponíveis, não se esgotando, contudo, as possibilidades existentes.

\section{Interação dos grupos de pesquisa do CNPq com o setor produtivo}

Esta seção introduz a interação universidade-empresa no Brasil a partir de informações disponíveis no Diretório dos Grupos de Pesquisa para o ano de 2004. A primeira parte é uma breve caracterização das instituições com grupos de pesquisa vinculados que declararam relacionamento com o setor produtivo e, também, dos agentes do setor produtivo que interagiram com os grupos de pesquisa de acordo com a natureza jurídica e tamanho do estabelecimento. A segunda parte apresenta os relacionamentos dos grupos de pesquisa com o setor produtivo por grande área do conhecimento. A terceira parte traz os tipos de relacionamentos entre os grupos de pesquisa e as empresas privadas e empresas públicas ou de economia mista, excluindo-se os relacionamentos com as Entidades sem Fins Lucrativos e as Administraçooes Públicas.

\subsection{Caracterização das instituições e das empresas}

Esta seção caracteriza as instituições com grupos de pesquisa vinculados ao CNPq cujo líder declarou algum tipo de relacionamento com o setor produtivo. A classificação das instituições foi realizada a partir da base de dados Apollo da ABPTI - Associação Brasileira das Instituições de Pesquisa Tecnológica e da base das Instituições de C\&T do Prossiga (Programa de Informação para Gestão de Ciência, Tecnologia e Inovação), do IBICT - Instituto Brasileiro de 
Informação em Ciência e Tecnologia (IBICT) na identificação da natureza das instituições, universidades e organizações cadastradas no Diretório. Para o Censo 2004, aproximadamente $97 \%$ das instituições foram passíveis de identificação nas referidas bases de dados.

A Tabela 2 traz as informações sobre o total de instituições e dos grupos de pesquisas vinculados que colaboraram com o setor produtivo em cada categoria institucional. Os grupos de pesquisa vinculados às Instituições de Ensino Superior (IES) públicas (federal, estadual e municipal) reúnem cerca de $73 \%$ do total dos grupos de pesquisa com relacionamento. Em seguida, vêm os grupos vinculados às IES Particulares (14\%), às Entidades de P\&D (8\%) e às Empresas de Pesquisa Agropecuária (4\%). ${ }^{8}$

Por outro lado, em termos do número de instituições observa-se que preponderância é das IES Particulares, que contabilizam 33,2\% do total, vindo em seguida as IES Federais com 26\%. Isto revela uma maior concentração dos grupos de pesquisa com relacionamentos com o setor produtivo nas IES Federais, possivelmente pelas mesmas abrangerem um conjunto mais amplo de competências científicas. O mesmo, geralmente, não é observado nas IES Particulares que tendem a possuir competências específicas nas especialidades do conhecimento. O mesmo padrão é observado para as Entidades de P\&D que tendem a ser especializadas em competências específicas (respondem por 18,3\% do total das instituições e por 7,5\% dos grupos de pesquisa). Esse panorama reflete uma participação significativa do sistema público de pesquisa no relacionamento com o setor produtivo nesta base de dados.

As informações sobre agentes do setor produtivo que se relacionaram com os grupos de pesquisa foram fornecidas pelos líderes dos grupos de pesquisa. Em 2004 esse total foi de 2.768 empresas e ou instituições. O módulo do questionário destina-se a identificar relacionamentos com o setor produtivo, mas os líderes também o utilizaram para descrever relacionamentos com outros agentes e instituições. A Tabela 3 traz esta distribuição em termos de natureza jurídica e tamanho do estabelecimento. ${ }^{9}$ Nota-se que $10,1 \%$ das instituições são Entidades sem Fins Lucrativos e 17,5\% são Administrações Públicas, que

8 Preponderância absoluta da EMBRAPA.

9 Foi adotada a classificação do SEBRAE por número de empregados: microempresas até 19 empregados; empresas pequenas de 20 a 99 empregados; empresas médias de 100 e 499 empregados e empresas grandes com mais de 500 empregados. 
TABELA 2

Total de instituições e de grupos de pesquisa com relacionamentos por categoria institucional dos grupos de pesquisa que relacionaram com o setor produtivo, Brasil, 2004

Categoria

IES Federal

IES Estadual

IES Particular

Entidade de P\&D

Empresa de Pesquisa Agropecuária

IES Municipal

Associação de Classe/Sociedade

SENAI

Centro Tecnológico

Incubadora

Outros (1)

Total
Número de instituições

Número

54

32

69

38

6

3

1

2

2

1

9

208
$\%$

26,0

15,4

33,2

18,3

2,9

1,4

0,5

1,0

1,0

0,5

4,3

100,0
Grupos com relacionamento Número $\quad \%$

$1.080 \quad 50,5$

453

21,2

305

14,3

161

7,5

3,8

1,8

0,4

0,2

0,1

0,2

120,6

$2.139 \quad 100,0$

Fonte: Diretório dos Grupos de Pesquisa do CNPq, Censo 2004, Apollo/ABIPTI, Prossiga (elaboração própria). Nota: (1) Instituições não identificadas na Base Apollo e no Prossiga.

contemplam respectivamente, por exemplo, associações, prefeituras, ministérios e secretárias de Estado.

As empresas privadas totalizam cerca de $68 \%$ do total e as Empresas Públicas e de Economia Mista 3,8\%. Estas últimas abrangem dentre outras, empresas dos setores de produção e distribuição de energia elétrica, de captação, tratamento e distribuição de água e de fabricação de coque, de álcool e de combustíveis nucleares, refino de petróleo. Em termos de tamanho as maiores participação relativa nos relacionamentos com grupos de pesquisa foram das micro $(31,5 \%)$ e grandes $(27,5 \%)$ empresas. Este comportamento, a principio, vai de encontro ao identificado na literatura (curva de cooperação por tamanho de empresa em forma de U).

\subsection{Grande área do conhecimento}


TABELA 3

Distribuição das empresas que relacionaram com os grupos de pesquisa, por tamanho e natureza jurídica, Brasil, 2004

\begin{tabular}{|c|c|c|c|c|c|c|}
\hline Natureza Jurídica & Micro & Pequena & Média & Grande & \multicolumn{2}{|c|}{ Total } \\
\hline Administração Pública & 27 & 15 & 63 & 174 & 279 & $10,1 \%$ \\
\hline Entidades sem Fins Lucrativos & 266 & 74 & 71 & 73 & 484 & $17,5 \%$ \\
\hline $\begin{array}{l}\text { Empresas Públicas e de } \\
\text { Economia Mista }\end{array}$ & 8 & 5 & 23 & 68 & 104 & $3,8 \%$ \\
\hline Empresas Privadas & 668 & 358 & 420 & 446 & 1.892 & $68,4 \%$ \\
\hline $\begin{array}{l}\text { Tamanho e ou natureza } \\
\text { jurídica ignorados }\end{array}$ & 2 & - & - & 1 & 9 & $0,3 \%$ \\
\hline & 971 & 452 & 577 & 762 & 2.768 & $100,0 \%$ \\
\hline \multicolumn{7}{|l|}{ Total } \\
\hline & $31,5 \%$ & $16,3 \%$ & $20,8 \%$ & $27,5 \%$ & $100,0 \%$ & \\
\hline
\end{tabular}

Fonte: Diretório dos Grupos de Pesquisa do CNPq, Censo 2004, elaboração própria.

Os grupos de pesquisa são cadastrados de acordo com a árvore de especialidade do conhecimento, que são oito, a saber: Engenharias, Ciências Agrárias, Ciências Biológicas, Ciências da Saúde, Ciências Exatas e da Terra, Ciências Humanas, Ciências Sociais e Aplicadas e Lingüística, Letras e Artes. A Tabela 4 traz a distribuição dos grupos de pesquisa (total e com relacionamento) e das empresas e/ou instituições que se relacionaram com os grupos de pesquisa por grande área do conhecimento. A tabela traz também dois indicadores: grau de interação - total dos grupos de pesquisa com relacionamento sobre o total dos grupos de pesquisa; e densidade de interação - total das empresas/instituições sobre os grupos de pesquisa com relacionamento.

Os grupos de pesquisa mais interativos, de acordo com o indicador proposto ( $3^{\mathrm{a}}$ coluna da tabela), foram os das grandes áreas de Engenharias (26,4\%) e Ciências Agrárias (21,7\%). Na grande área de Engenharias esse desempenho 
TABELA 4

Grupos de pesquisa, total e com relacionamento, empresas/instituições, grau de interação e densidade de interação por grande área do conhecimento, Brasil, 2004

\begin{tabular}{|c|c|c|c|c|c|}
\hline $\begin{array}{l}\text { Grande área do } \\
\text { conhecimento }\end{array}$ & Grupos & $\begin{array}{l}\text { Grupos com } \\
\text { relacionamento } \\
\text { (b) }\end{array}$ & $\begin{array}{c}\text { Grau de } \\
\text { interação } \\
\text { (b)/(a) }\end{array}$ & $\begin{array}{c}\text { Empresas / } \\
\text { Instituições } \\
\text { (c) }\end{array}$ & $\begin{array}{c}\text { Densidade } \\
\text { de interação } \\
\text { (c)/(b) }\end{array}$ \\
\hline Engenharias & 2.826 & 747 & $26,43 \%$ & 1.301 & 1,74 \\
\hline Ciências Agrárias & 1.997 & 434 & $21,73 \%$ & 684 & 1,58 \\
\hline Ciências Exatas e da Terra & 2.454 & 248 & $10,11 \%$ & 335 & 1,35 \\
\hline Ciências da Saúde & 3.371 & 236 & $7,00 \%$ & 270 & 1,14 \\
\hline Ciências Biológicas & 2.561 & 224 & $8,75 \%$ & 319 & 1,42 \\
\hline Ciências Sociais Aplicadas & 2.120 & 130 & $6,13 \%$ & 211 & 1,62 \\
\hline Ciências Humanas & 3.088 & 108 & $3,50 \%$ & 174 & 1,61 \\
\hline Lingüística, Letras e Artes & 1.053 & 24 & $2,28 \%$ & 26 & 1,08 \\
\hline Totais & 19.470 & 2.151 & $11,05 \%$ & 2.768 & 1,29 \\
\hline
\end{tabular}

Fonte: Diretório dos Grupos de Pesquisa do CNPq, Censo 2004, elaboração própria.

pode ser explicado pela tradição de sempre ter o ensino e a pesquisa voltados e próximos às praticas produtivas e industriais. $\mathrm{O}$ comportamento das Ciências Agrárias pode, em parte, ser explicado por constituir-se em uma área que contou com incentivos e financiamentos governamentais para o seu desenvolvimento visando o aumento da competitividade do setor agroexportador.

Em seguida, vêm as grandes áreas de Ciências Exatas e da Terra (10,11\%), Ciências Biológicas (8,75\%) e Ciências da Saúde (7\%). Preocupante é o desempenho destas duas últimas grandes áreas, visto a competência nacional existente e as potencialidades recentes de parceria com o setor privado, como é no caso das áreas correlatas à biotecnologia. Estes exemplos evidenciam o pouco aproveitamento pelo setor produtivo do conjunto de oportunidades tecnológicas oferecidas pela infra-estrutura nacional de C\&T (Cassiolato et al., 1996). 
Em termos da densidade de interação os maiores índices foram em Engenharias (1,74), Ciências Sociais Aplicadas $(1,62)$, Ciências Humanas $(1,61)$ e Ciências Agrárias $(1,58)$, reflexo de uma maior diversificação nas parcerias com as empresas/instituições. Para estas últimas grandes áreas a literatura, inclusive, vem apontando para uma maior interação das universidades com empresas do setor de serviços (Schartinger et al., 2002).

A Tabela 5 traz a distribuição dos tipos de relacionamentos em cada grande área do conhecimento. ${ }^{10} \mathrm{O}$ primeiro bloco reúne os relacionamentos oriundos dos grupos de pesquisa tendo como destino o setor produtivo. Os mesmos contabilizaram aproximadamente $92 \%$ do total, apontando para um fluxo quase unidirecional de relacionamentos que parte primordialmente das universidades e instituiçôes públicas de pesquisa para o setor produtivo. A maior parcela de relacionamentos oriundos do setor produtivo para os grupos de pesquisa (segundo bloco) ocorreu na grande área de Engenharias.

Os relacionamentos predominantes provenientes dos grupos de pesquisas para o setor produtivo (primeiro bloco) foram: pesquisa científica com considerações de uso imediato dos resultados (2.731 ou 30\% do total); transferência de tecnologia (1.502 ou 17\%) e pesquisa científica sem considerações de uso imediato dos resultados (1.412 ou 16\%). As atividades de consultoria técnica aparecem na quarta posição (com 772 ou 8,3\%).

A liderança dos relacionamentos em pesquisas científicas sugere trocas bidirecionais de conhecimento, distintas das trocas em uma única direção características das consultorias técnicas. Esse panorama pode estar apontando para avanços no desenvolvimento de uma linguagem em comum entre os grupos de pesquisa e o setor produtivo. Em termos de especificidades setoriais as atividades de engenharia não-rotineira e de desenvolvimento de software foram principalmente realizadas pelos grupos de pesquisa das Engenharias.

O segundo bloco da tabela traz a freqüência dos relacionamentos procedentes do setor produtivo para os grupos de pesquisa. A liderança foi das atividades de transferência de tecnologia (260) e do treinamento de pessoal (225). Esta última atividade possivelmente compreende estágios fornecidos a membros dos grupos de pesquisa. Esta configuração confirma o observado

\footnotetext{
${ }^{10}$ Foram excluídos os relacionamentos referentes ao fornecimento de insumos e matérias-primas conforme descrito na metodologia.
} 
TABELA 5

Tipos de relacionamento dos grupos de pesquisa com o setor produtivo por grande área do conhecimento, Brasil, 2004

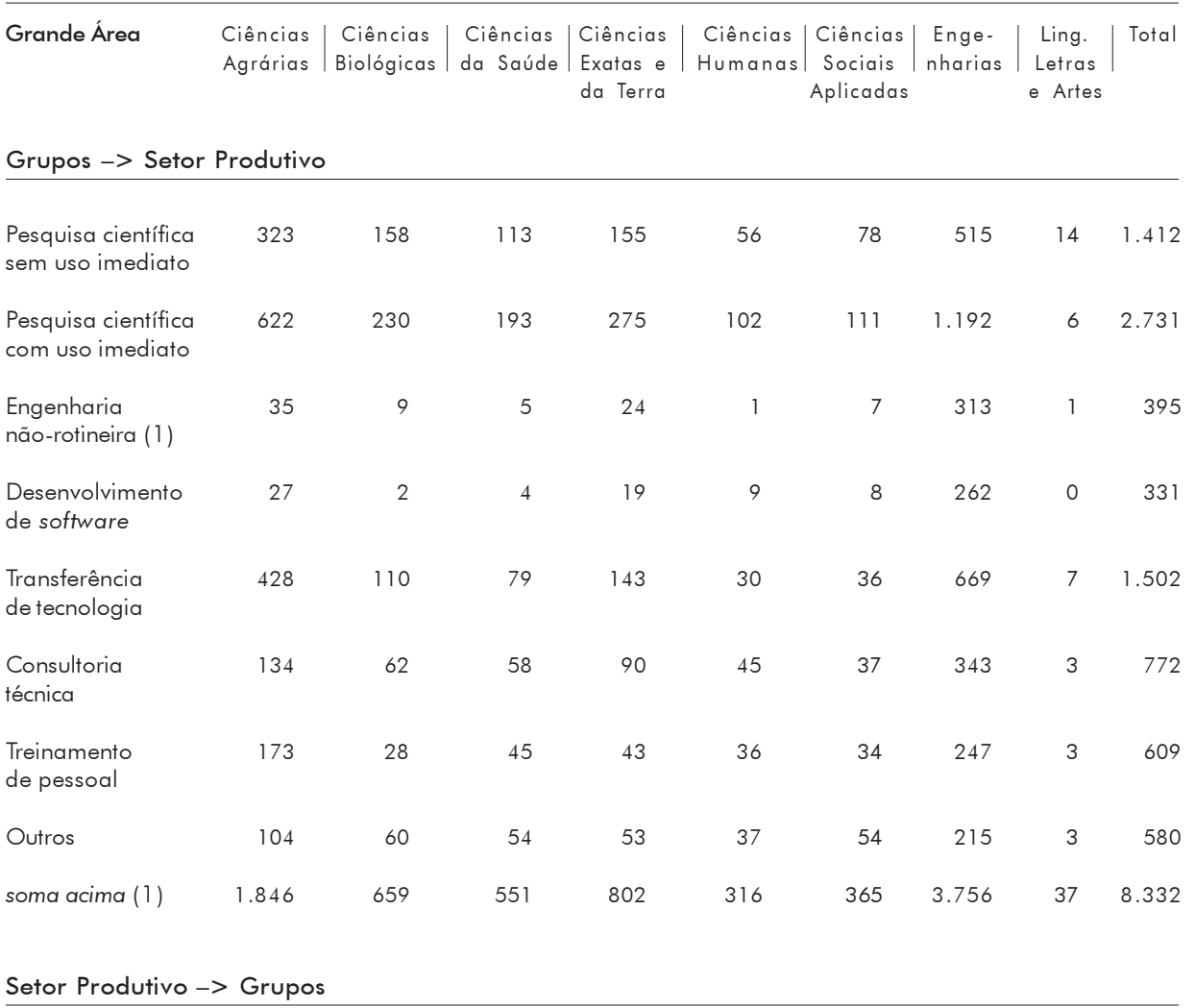

\begin{tabular}{|c|c|c|c|c|c|c|c|c|c|}
\hline $\begin{array}{l}\text { Engenharia } \\
\text { não-rotineira (2) }\end{array}$ & 8 & 1 & 5 & 30 & 0 & 0 & 62 & 0 & 106 \\
\hline $\begin{array}{l}\text { Desenvolvimento } \\
\text { de software }\end{array}$ & 6 & 6 & 5 & 4 & 4 & 6 & 89 & 9 & 129 \\
\hline $\begin{array}{l}\text { Transferência } \\
\text { de tecnologia }\end{array}$ & 82 & 31 & 25 & 16 & 9 & 17 & 75 & 5 & 260 \\
\hline $\begin{array}{l}\text { Treinamento } \\
\text { de pessoal }\end{array}$ & 49 & 21 & 29 & 21 & 14 & 14 & 76 & 1 & 225 \\
\hline soma acima (2) & 145 & 59 & 64 & 71 & 27 & 37 & 302 & 15 & 720 \\
\hline Total (1) + (2) & 2.171 & 767 & 676 & 908 & 358 & 416 & 4.313 & 53 & 9.052 \\
\hline
\end{tabular}

Fonte: Diretório dos Grupos de Pesquisa do CNPq, Censo 2004, elaboração própria.

Notas: (1) inclusive o desenvolvimento de protótipo cabeça de série ou planta piloto para a empresa.

(2) inclusive o desenvolvimento fabricação de equipamentos para o grupo. 
anteriormente sobre a tendência de um estreitamento dos fluxos de conhecimento entre os grupos de pesquisa e o setor produtivo.

\subsection{Tamanho da empresa}

Essa seção traz os tipos relacionamentos entre os grupos de pesquisa e o setor privado excluindo-se as Administrações Públicas, as Entidades sem Fins Lucrativos e os estabelecimentos de natureza jurídica ignorada. As mesmas contabilizam 772 estabelecimentos (ver Tabela 3) e totalizam 2.498 relacionamentos. O objetivo desta seção é analisar a interação dos grupos de pesquisa somente com as empresas privadas e as empresas públicas e de economia mista. A Tabela 6 traz os dados de acordo com o tamanho do estabelecimento.

Uma primeira observação remete à participação das grandes empresas que respondem por mais da metade do total dos relacionamentos das empresas privadas e empresas públicas e de economia mista. É importante notar que, em termos absolutos, elas são em número inferior às microempresas (514 versus 676). Isto pode ser explicado pelo fato delas terem melhores condições de explorar a base de conhecimento externo, conforme apontado na literatura, portanto estariam se engajando em mais relacionamentos com os grupos de pesquisa.

O primeiro bloco da tabela traz os tipos de relacionamentos oriundos dos grupos de pesquisa para as empresas. Seguem o padrão descrito na seção anterior, sendo os mais freqüentes: pesquisa científica com consideraçōes de uso imediato dos resultados (2.018); transferência de tecnologia (1.160), pesquisa científica sem considerações de uso imediato dos resultados (968) e atividades de consultoria técnica (550).

Dos relacionamentos provenientes das empresas para os grupos de pesquisa (segundo bloco da tabela) o desempenho das microempresas foi muito próximo ao das grandes empresas (187 versus 191 total de relacionamentos). Uma das explicações pode ser que as microempresas, por não disporem de recursos internamente, estreitam os relacionamentos com os grupos de pesquisa, inclusive tornando-os mais freqüentes. Conseqüentemente transferem mais recursos e produtos aos grupos de pesquisa como é observado na tabela onde lideram todos os relacionamentos, com exceção da transferência de tecnologia. 
TABELA 6

Tipos e números de relacionamentos das empresas privadas e empresas públicas e de economia mista por fluxo de origem e tamanho, Brasil, 2004

\begin{tabular}{|c|c|c|c|c|c|c|}
\hline Grupos -> Empresas & Micro & Pequena & Média & Grande & lgnorado & Total \\
\hline Consultoria técnica & 108 & 86 & 92 & 262 & 2 & 550 \\
\hline Engenharia não-rotineira & 81 & 55 & 55 & 152 & 0 & 343 \\
\hline Desenvolvimento de software & 40 & 16 & 37 & 174 & 0 & 267 \\
\hline Pesquisa científica com uso imediato & 398 & 251 & 363 & 1.002 & 4 & 2.018 \\
\hline Pesquisa científica sem uso imediato & 201 & 115 & 168 & 483 & 1 & 968 \\
\hline Transferência de tecnologia & 271 & 146 & 239 & 502 & 2 & 1.160 \\
\hline Treinamento de pessoal & 79 & 29 & 67 & 233 & 2 & 410 \\
\hline Outros & 70 & 31 & 57 & 159 & 0 & 317 \\
\hline Soma acima (1) & 1.248 & 729 & 1.078 & 2.967 & 11 & \\
\hline Empresas $->$ Grupos & & & & & & \\
\hline Engenharia não-rotineira & 33 & 13 & 11 & 27 & 0 & 0 \\
\hline Desenvolvimento de software & 48 & 10 & 9 & 36 & 0 & 84 \\
\hline Transferência de tecnologia & 54 & 18 & 25 & 80 & 0 & 103 \\
\hline Treinamento de pessoal & 52 & 20 & 37 & 48 & 0 & 177 \\
\hline Soma acima (2) & 187 & 61 & 82 & 191 & 0 & 157 \\
\hline Total $[(1)+(2)]$ & 1.567 & 872 & 1.254 & 3.302 & 12 & 6.554 \\
\hline Total de empresas & 676 & 363 & 443 & 514 & 4 & 2.000 \\
\hline
\end{tabular}

Fonte: Diretório dos Grupos de Pesquisa do CNPq, Censo 2004, elaboração própria.

Nota: (1) inclusive o desenvolvimento de protótipo cabeça de série ou planta piloto para a empresa.

(2) inclusive o desenvolvimento fabricação de equipamentos para o grupo. 


\section{Conclusão}

O artigo apresentou a base de dados do Diretório dos Grupos de Pesquisa do CNPq com foco nos relacionamentos entre os grupos de pesquisa com o setor privado declarados pelos líderes dos grupos, tendo como exemplo o Censo 2004. Mesmo que contemplando uma pequena parcela da comunidade científica nacional, o Diretório apresenta-se como instrumentos auxiliar na investigação do tema interação universidade-empresa, conforme demonstrado pelo trabalho.

O exame no nível institucional revela uma baixa participação dos grupos de pesquisa em interações com empresas, que acrescido do universo das instituiçôes sem grupos de pesquisa que interagiram com empresas, indica uma subestimação das relações de colaboração com empresas declaradas pelos líderes vis-à-vis a existente. Supóe-se que o universo das relaçóes entre os grupos de pesquisa e as empresas seja muito maior do que as relaçóes captadas. Infere-se, além da natureza compulsória das respostas, deficiências inerentes ao questionário e ao conteúdo de opções abrangidas que provavelmente limitam o preenchimento.

As áreas do conhecimento com maior participação nos relacionamentos, Engenharias e Ciências Agrárias, são compatíveis com o modelo de industrialização brasileiro e com incentivos públicos específicos de desenvolvimento setorial. Não há associação entre a capacitação científica e a colaboração com empresas como exemplificado pelas áreas de Ciências Biológicas e Ciências da Saúde. Nestes casos, estímulos que levem a uma maior atuação do setor privado permitirão um melhor aproveitamento das competências e oportunidades existentes.

Em termo institucional, a preponderância foi dos grupos de pesquisa vinculados às IES Federais, que dado o processo de construção histórica, tendem a agregar um maior número de competências científicas. Há, contudo, um amplo espaço de incremento à colaboração com o setor produtivo. Por parte das empresas, as interaçôes mais freqüentes com os grupos de pesquisa remeteram às grandes empresas, possivelmente pelas mesmas terem melhores condições de explorar a base de conhecimento externo.

À primeira vista, parte significativa dos relacionamentos é um fluxo unidirecional oriundo das universidades e instituições para as empresas. Os resultados, contudo, evidenciam que as maiores frequiências são das atividades vinculadas às pesquisas científicas e à transferência de tecnologia que se caracterizam 
como trocas bidirecionais de conhecimento, o que sugere avanços no desenvolvimento de uma linguagem em comum entre os grupos de pesquisa e o setor produtivo.

Este cenário também indica um papel adicional desempenhado pelas universidades e instituições de pesquisa no País na complementariedade e/ou substituição de atividades de pesquisa realizadas pelas empresas. Isto vai de encontro à suposição de Albuquerque et al. (2005) da alta valorização das universidades por parte de empresas que não possuem atividades de P\&D. É necessário uma melhor compreensão desta dinâmica, sendo estudos de caso pontuais, talvez, ilustrativas formas de evidenciar estes mecanismos operantes.

Portanto, tem-se o estreitamento e a sofisticação dos processos colaborativos entre empresas e universidades, constatados pelo Censo 2004 do Diretório dos Grupos de Pesquisa do CNPq, mas este referente a um grupo restrito de grupos de pesquisa e empresas. Ainda há muito espaço para aumento da interação universidade-empresa como mecanismo capaz de fomentar a aquisição de insumos intangíveis fundamentais para a geração e desenvolvimento de tecnologias internamente.

Como agenda de pesquisa futura enumeram-se pelo menos três desdobramentos:

a) uma investigação detalhada das complementaridades e diferenças existentes entre a base do Diretório dos Grupos de Pesquisa do CNPq e a Pesquisa de Inovação Tecnológica - PINTEC realizada pelo IBGE. Essas duas bases podem ser exploradas de forma complementar, na medida em que juntas conseguem reunir alguns dos atores da interação universidadeempresa no País: os grupos de pesquisa cadastrados no CNPq e empresas que realizaram inovação;

b) uma investigação da percepção dos líderes dos grupos de pesquisa sobre as respostas atribuídas às interações com o setor produtivo, seja com estudos de caso ou entrevistas realizadas aos mesmos;

c) o desenvolvimento e concepção de indicadores voltados às interações universidade-empresa no âmbito de indicadores de C\&T para Países em desenvolvimento. 


\section{Referências bibliográficas}

Acts, Z.J.; Audretsch, D.B.; Feldman, M.P., "Real effects of acadedmic research: Comment", The American Economic Review, v.82, n.1, p.363-367, 1992.

Associação Brasileira das Instituições de Pesquisa Tecnológica, 2003. Base Apollo. Disponível na internet (www.abipti.org.br). Acesso em 17 de novembro de 2003.

Albuquerque, E.M.; Silva, L.A.; Povoa, L., Diferenciação intersetorial na interação entre empresas e universidades no Brasil: notas introdutórias sobre as especificidades da interação entre ciência e tecnologia em sistemas de inovação imaturos. Texto para Discussão $N^{0}$ 264. Belo Horizonte: UFMG/ CEDEPLAR, 20 p., 2005.

Audretsch, D.B.; Stephan, P.E., "Company- Scientist Locational Links: The Case of Biotechnology", The American Economic Review, v.86, n.3, p.641-652, jun., 1996.

Breschi, S.; Lissoni, F., "Knowledge Spillovers and Local Innovation Systems: A Critical Survey", Industrial and Corporate Change, v.10, n.4, p.975-1.005, 2001.

Brisolla, S.; Corder, S.; Gomes, E.; Mello, D., "As relações universidade-empresa-governo: Um estudo sobre a Universidade Estaual de Campinas", Educação \& Sociedade, ano XVIII, n.61, dez., 1997.

Carneiro, S.J.; Lourenço, R., "Pós-Graduação e Pesquisa na Universidade", in Viotti, E. B.; Macedo, M. (orgs.), Indicadores de Ciência, Tecnologia e Inovação no Brasil, Campinas: Editora da Unicamp, cap.4, p.169-227, 2003.

Cassiolato, J.E.; Lastres, H.M.M. (orgs.), Globalização e inovação localizada: experiências de sistemas locais no Mercosul, Brasília: IBICT/MCT, 1996.

CNPq - Conselho Nacional de Desenvolvimento Científico e Tecnológico, 2005. Disponível na internet (www.cnpq.br). Acesso em 5 de julho de 2005.

Cohen, W.M.; Nelson, R.R.; Walsh, J.P., "The influence of Public Research on Industrial R\&D”, Management Science, v.48, n.1, p.1-23, January, 2002.

Cruz, C.H.B. "Universidade, empresa e a inovação tecnológica", Interação Universidade Empresa, Brasília: IBCT, v.1, p.226-240, 1999.

Dorfman, N.S. "Route 128: The development of a regional high technology economy". Research Policy, v.12, n.6, dez., p.299-316, 1989. 
Instituto Brasileiro de Informação em Ciência e Tecnologia, 2005. Programa Prossiga. Disponível na internet (www.prossiga.ibict.br). Acesso em 10 de julho de 2005.

Instituto Brasileiro de Geografia e Estatística, 2005. Pesquisa Industrial Inovação Tecnológica 2003. Comentários. Disponível na internet (www.ibge.gov.br). Acesso em 14 de julho de 2005.

Faulkner, W.; Senker, J., "Making sense of diversity: public-private sector research linkages in three technologies", Research Policy, v.23, n.6, p.673-695, nov., 1994.

Jaffe, A.B .; Trajtenberg, M; Henderson, R. "Geographic Localization of knowledge spillovers as evidence by patent citation", The Quartely Journal of Economics, v.108, n.3, p.577-598, ago., 1993.

Klevorick, A.K.; Levin, R.; Nelson, R.R.; Winter, S., "On the sources and significance of inter-industry differences in technological opportunities", Research Policy, v.24, n.2, p.185-205, mar., 1995.

Lundvall, B.A., "The University in the Learning Economy", DRUID Working Paper, n.2-6, 2002.

Mansfield, E.; Lee, J. “The modern university: contributor to industrial innovation and recipient of industrial P\&D support", Research Policy, v.25, n.7, out., p.1.047-1.058, 1996.

Meyer-Kramer, F.; Schmoch, U., "Science-based technologies: university-industry interactions in four fields", Research Policy, v.27, n.8, p.835-851, dez., 1998.

Monjon, S.; Waelbroeck, P., "Assessing spillovers from universities to firms: evidence from French firm-level data", International Journal of Industrial Organization, v.21, p.1.255-1.270, 2003.

Mowery, D.C.; Sampat, B.N., "Universities in National Innovation Systems", in Fagerberg, J.; Mowery, D.C.; Nelson, R.R. (orgs.), The Oxford Handbook of innovation, Oxford: Oxford University Press, 2005.

Nelson, R.R., "Capitalism as an engine of progress", Research Policy, v.19, n.3, p.193-214, jun., 1990.

Pavitt, K., "The Social Shaping of the national science base", Research Policy, v.27, n.8, p.793-805, 1998.

Rappel, E., "Integração universidade-indústria: os 'porques' e os 'comos”, Interação Universidade Empresa, Brasília: IBICT, v.2, p.90-106, 1999. 
Rapini, M.S., Interação Universidade-Indústria no Brasil: Uma análise exploratória a partir do Diretório de Pesquisas do CNPq. Dissertação de Mestrado apresentada ao Instituto de Economia da UFRJ, Rio de Janeiro, 2004.

Rosenberg, N., "Scientific instrumentation and univeristy research?", Research Policy, v.21, n.4, p.381-390, ago., 1992.

Rosenberg, N; Nelson, R.R., "American university and technical advance in industry", Research Policy, v.23, n.3, p.323-348, maio, 1994.

Salter, A.; Martin, B., "The economic benefits of publicly funded basic research: a critical review”, Research Policy, v.30, n.3, p.509-532, mar., 2001.

Schartinger, D.; Shibany, A.; Gassler, H. "Interactive relations between universities and firms: empirical evidence for Austria", Journal of Technology Transfer, v.26, p.255-268, 2001.

Schartinger, D.; Rammer, C.; Fisher, M.M.; Fröhlich, J., "Knowledge interactions between universtities and industry in Austria: sectoral patterns and determinants", Research Policy, v.31, n.3, p.303-328, mar., 2002.

Schimank, U. "The contribution of university research to the technological innovation of the German economy: societal auto-dynamic nad political guidance", Research Policy, v.17, p.329-340, 1988.

Silva, L.E.; Mazzali, L., "Parceria tecnológica universidade-empresa: um arcabouço conceitual para a análise de gestão dessa relação”, Parcerias Estratégicas, n.11, jun., 2001.

Stankiewicz, R., "Spin-off companies from universities", Science and Public Policy, v.21, n.2, p.99-107, abr., 1994.

Varga, A., "Regional Economic Effects of University Research: A survey". Working Paper, Department for Economics Geography and Geoinformatics, University of Economics and Business Administration, Vienna, 1997.

Vargas, M.A.; Filho, N.S.; Alievi, R.M., "Sistema gaúcho de inovação: avaliação de arranjos locais selecionados", in Cassiolato, J.E.; Lastres, H.M.M. (orgs.), op. cit.

Velho, L., Relaçôes Universidade-Empresa:Desvelando Mitos. Campinas,: Autores Associados, Coleção educação contemporânea, 1996. 